\title{
Influencing Environmentally Sustainable Consumer Choice through Information Transparency
}

\author{
Dorothy E. Leidner \\ Baylor University \\ Dorothy_Leidner@baylor.edu
}

\author{
Juliana Sutanto \\ Lancaster University \\ j.sutanto@1ancaster.ac.uk
}

\author{
Lazaros Goutas \\ Loughborough University \\ L.Goutas@,1boro.ac.uk
}

\begin{abstract}
A number of studies have argued that recent technological and informational affordances have enabled a greater degree of transparency, which can in turn guide consumer behavior towards more sustainable patterns of consumption. This paper examines whether sustainability attribute information influences sustainable product choice. Our hypotheses are driven by construal level theory and tested through a stated choice experiment in the context of a selfdeveloped online grocery store. Our results show that the mere disclosure of sustainability information does not influence consumers to choose a sustainable product. Rather, the effect of sustainability information on sustainable product choice depends on the sustainability attributes provided. We discuss the contributions of our study to the literature and the implications for practitioners.
\end{abstract}

\section{Introduction}

Sustainable consumption is "the use of goods and related products which respond to basic needs and bring a better quality of life, while minimizing the use of natural resources and toxic materials as well as the emissions of waste and pollutants over the life cycle, so as not to jeopardize the needs of future generations" (Norwegian Ministry of Environment as cited in [1] p. 2). This broad definition applies to the economic, environmental and social impact of consumption, which in turn reflects the triple bottom line of environmental sustainability, also termed as the 3Ps (Profit, Planet, People) of environmental sustainability [2]. Sustainable consumption is sometimes referred to as ethical consumption. In this paper, we will use these terms interchangeably. A favorable disposition toward sustainable consumption has been gaining momentum: for instance, $66 \%$ of consumers are willing to pay extra for sustainable offerings [3]. The United Nations Sustainable Development Goal 12 is to ensure sustainable consumption and production patterns.
However, the positive attitudes towards sustainable consumption in many cases fails to materialize into substantive action [4]. In food choice, as in many other product categories, most consumers claim to consider sustainability issues generally important and desirable, but this does not necessarily translate into actual sustainable consumer behavior [5]. It seems that the attributes that most consumers claim to be important are not always a good predictor of the attributes that actually determine their choices [6].

The provision of increased access to information regarding product attributes has been considered key in terms of fostering sustainable consumption [7, 8, 9]. With social media, mobile applications and network communities, consumers are empowered to overcome information asymmetries and have more knowledge about product attributes [10]. At the same time, evidence suggests that consumers in online environments are more likely to shop more sustainably than in physical ones, because at the comfort of their computer, consumers have enough time to scrutinize any given information and pursue sustainably guided choices $[11,12,13]$.

Notwithstanding the promise of information systems (IS) in terms of encouraging sustainable consumption choices, a number of studies have questioned the efficacy of information transparency. For instance, there has been evidence of consumers being presented with information about certain product attributes, e.g., low wages of the people producing the product, but nevertheless expressing a preference for these products on the basis of price, value, fashion and trends [8]. In today's environment of potentially abundant information, consumer informedness does not come without costs. In particular, freedom of choice and expansion of information can result in decision complexity in terms of trade-off difficulty and preference uncertainty [14].

Against this backdrop, many organizations have struggled to effectively develop and manage a sustainability information transparency strategy, especially in the context of online environments. Is it 
true that consumers will always reward the companies that play it straight by paying a higher premium? Will consumers de facto punish products that do not rate as highly as others on certain sustainability attributes? The present paper seeks to examine whether differences in terms of the sustainability attribute information that is disclosed can potentially foster sustainable consumer choice. Given that our study deals with the topic of environmentally sustainable consumption, we differentiate between the disclosure of information around the 3Ps of environmental sustainability (i.e., People, Planet, Profit).

Our study is theoretically motivated by Construal Level Theory (CLT), which posits that objects and events are mentally represented (construed) at higher or lower levels of abstraction and that the mental representation influences individuals' choice of action [15]. Given that earlier works have shown that sustainability-related attribute information applies to high-level construals [16], we argue that the sustainability attribute information that is being disclosed will not be equally successful in terms of influencing sustainable choices because the sustainability attribute information is usually situated next to more concrete types of information (e.g. pricing information) that under certain conditions guide consumers away from the choice of sustainable products.

The rest of the paper is organized as follows: the next section summarizes the related works on information transparency. Section 3 outlines the theoretical background of our study and lists our hypotheses. Section 4 describes the design of our studies, whereas section 5 lists our empirical results. The final section discusses the implications of our findings and concludes.

\section{Literature review}

\subsection{Related research on information transparency}

The benefits (and pitfalls) of information transparency have largely been examined in the context of electronic marketplaces, where IT has enhanced the flow of information and led to the development of online platforms that have increased consumers' surplus and welfare $[17,18]$. Even within the area of sustainable consumption, which is our focus, earlier studies have argued that information availability on the ethical attributes of a product can influence consumers' purchase intentions [7, 9]. The state of higher informedness has also been reached by the increased use of mobile applications and social media.
A large component of the information generated by these channels consists of negative information, which can potentially carry significant implications for organizations. For instance, within the context of the hotel industry, Clemons and Gao [19] found that the presence of hostile reviews and negative words was the best predictor of a hotel's inability to sell rooms online, while the absence of negative reviews was the best predictor of its ability to sell rooms. In light of the above, organizations are increasingly becoming more active in managing negative information and making it part of their broader transparency strategy.

The potential effects of negative information disclosure have been examined in the consumer behavior literature, primarily in the context of public relations, publicity and word of mouth communications. A common argument in this literature is that negative information affects product impressions and evaluations [20]. Nevertheless, empirical results about its effects tend to be mixed [21]. While a number of studies have suggested that negative information produces negative effects on consumer choice by undermining consumers' original impressions, other studies have found positive effects of negative information, for instance by raising product awareness and accessibility [20], or by enhancing the initial favorable impressions that might have arisen from positive information [22]. Within the area of sustainable consumption, existing studies have shown that the availability of negative information does not influence consumer attitudes any more than does the exposure to positive attribute information [8].

\subsection{Information transparency and sustainable consumption}

Evidence suggests that consumers are increasingly concerned about sustainability problems and are accordingly demanding more information about products' sustainability-related attributes [23]. In fact, in certain cases consumers are willing to pay premium prices to support the ethical movement [5, 13, 24]. When informed about ethical practices by corporations, consumers tend to form a positive attitude toward the latter [25]. However, studies have also shown that consumers would use attribute information more frequently if they did not have to seek it out. If consumers had the information in hand, they would be more inclined towards sustainable consumption behavior [26]. At the same time, in certain cases consumers may be overwhelmed by increased informedness: consumers can feel afraid that access to information will increase their decision difficulty or charge them emotionally with stress and anxiety, and hence, prefer to stay willfully ignorant [26] especially 
when they are not so concerned with appearing socially responsible to others [27].

Technological advances in product traceability systems have further eased consumers' access to information and to more informed product choices. Through these advances, consumers are now enabled to know more about the origins, history, and the production methods of a product [28]. Digital artifacts can further enhance consumer informedness and pose a useful tool for communicating firms' information strategies [25]. Generally, this increased access to information is acknowledged to inculcate sustainable consumption patterns $[27,28]$. We argue that the relationship between the provision of sustainability attribute information and sustainable consumption through digital artifacts is not that simple. Our hypotheses are informed by construal level theory, which we describe in the next section.

\section{Theoretical background and hypotheses}

The main tenet of Construal Level Theory (CLT) is that objects and events are mentally represented (construed) at different levels of abstraction, which in turn affects individuals' type of reasoning and choices. As Trope and Liberman [29, p. 451] note, "We make choices and set preferences with respect to our construals of objects rather than the objects themselves. When we choose a car, we do not decide on the car itself but rather on our construal of the car. When we decide on a diet, we do so because the construal of its outcomes seems attractive to us".

Construals are known to be dependent on the psychological distance, which is determined by temporal, spatial, and social distance as well as probabilistic distance [29]. Psychological distance can refer to a person's perceptions of temporal distance (how much time --past or future-- separates between the perceiver's present time and the target event), spatial distance (how distal in space is the target from the perceiver), social distance (how distinct is the social target from the perceiver's self, e.g. self vs. others, friend vs. stranger), or probabilistic distance (how likely is the target event to happen, or how close it is to reality, as construed by the perceiver) [30]. Bar-Anan et al. [30, p. 609] offer an indicative example of the different forms of psychological distance: “...the event 'I am here, now, in reality, reading a paper" is psychologically proximal, because it describes direct experience. This event can become more psychologically distant if we think of someone else performing the same action (e.g., 'My advisor is here, now, in reality, reading a paper.')".

As psychological distance increases, individuals tend to represent stimuli at a higher level by decontextualized and simple features that convey the stimuli essence. As psychological distance decreases, individuals will tend to represent the same stimuli at a lower level by contextualized and specific features that convey the details of the stimuli [31]. In other words, high-level (low-level) construals apply to psychologically distant (proximate) choices or outcomes and to abstract (concrete) representations of these choices and outcomes. Accordingly, as the psychological distance from a choice or an outcome increases, individuals tend to focus more on the desirability of an outcome, whereas in cases of lower psychological distance, the focus shifts towards the feasibility of an outcome [32]. In sum, a key insight of CLT is that the way in which a stimulus is construed not only systematically influences individuals' ways of processing the information but also affects their resulting choices and decisions [31, 33].

The context of sustainable consumption is generally acknowledged to represent a social dilemma in the sense that individuals willing to engage in sustainable consumption are willing to forego some immediate personal benefits for some delayed collective benefit [34]. Given that sustainable choices pertain to outcomes that are both socially and temporally distant, their representation is based on high-level (more abstract) construals that concern desirability outcomes [15, 16]. However, the mere notion that information regarding a product's sustainability attributes is construed at a higher level of abstraction does not necessarily imply that consumers will select such products; it is known, for instance, that individuals are more likely to make unethical trade-offs in situations of higher psychological distance, where information is construed at a higher level [35].

Taking the above into account, we propose that in order to understand the conditions under which sustainable product choices occur, it is important to examine why the high-level construals associated with a product will predominate over the lower-level construals derived from concrete pieces of information (e.g. pricing information) about these products. To this effect, we argue that even in the case that lower (higher) construals are triggered, this does not necessarily imply that consumers will be more likely to prefer unsustainable (sustainable) products; in this case, the content of information also has a role to play in terms of influencing choice, since the different sustainability attributes are associated with different degrees of psychological distance.

Given that the presentation of sustainability attribute information, as compared to pricing information, will activate a high construal, we argue that sustainable products will be chosen in cases where psychological distance is the lowest. This can be the case among instances where sustainable behavior is 
perceived as being congruent with achieving personal benefits [15]. We therefore argue that sustainable choice will occur in situations where the sustainability attribute information is closely aligned with individuals' personal goals and standards. Under these conditions, the goalcompatibility effect between a product's sustainability attributes and its other attributes (e.g. pricing) will result in a reduced psychological distance, and thereby lead to sustainable product choices. Our hypotheses are therefore the following:

H1: The mere disclosure of sustainability-related information does not influence consumers to choose a sustainable product over an unsustainable product.

H2: When the sustainability attribute information has a stronger appeal to individual benefits, consumers will choose a sustainable product over an unsustainable product.

\section{Research design}

To test our hypotheses, we conducted a series of stated choice experiments, specifically within the context of online grocery shopping. Because ecommerce technologies have increased the overall ability of firms to strategize with market information and to develop innovative mercantile mechanisms that allow firms to develop an information transparency strategy [36], we consider online shopping to be a suitable setting to explore the disclosure of sustainability attribute information. As it becomes easier for consumers to source for and compare product information electronically [37, 38], organizations are facing increasing pressures to provide product attribute information to consumers in a transparent way. This experiment will help manufacturers, especially food producers, in developing information transparency strategies.

Stated choice experiments involve the presentation of a hypothetical choice situation to the participants who have to state their choice preferences among different alternatives [39, 40]. We self-developed an artificial online grocery store that presented three alternatives for each of the twelve grocery products that were available in the store (six fruits and vegetables, and six dairy products). The three alternatives for each product were: 1) an unsustainable product with negative information, 2) a sustainable product with positive information, and 3) a non-transparent product with no sustainability information. The participants were given a virtual wallet and were asked to purchase one among the three alternatives of the twelve grocery products. To prevent socially desirable purchasing, we ensured that the participants could not purchase all twelve products with positive information because the total cost of purchasing these products would have exceeded the money in their virtual wallet. If the total purchase was above the threshold, the participants were not able to check-out from the online grocery store and complete the experiment. We included this constraint in order to make the decision-making process more thoughtful and realistic.

To test our hypothesis, we conducted two experiments, with 52 participants in the first experiment and 53 participants in the second experiment. The demographic characteristics of the participants are shown in Table 1.

Table 1. Demographic characteristics of the experiments participants

\begin{tabular}{|l|l|l|}
\hline $\begin{array}{l}\text { Demographic } \\
\text { Characteristics }\end{array}$ & $\begin{array}{l}\text { First Experiment } \\
\text { Group }(N=52)\end{array}$ & $\begin{array}{l}\text { Second Experiment } \\
\text { Group }(N=53)\end{array}$ \\
\hline $\begin{array}{c}\text { Gender } \\
\text { Male }\end{array}$ & $27(51.92 \%)$ & $29(54.72 \%)$ \\
Female & $25(48.08 \%)$ & $24(45.28 \%)$ \\
\hline Age & & \\
$18-25$ years old & $19(36.54 \%)$ & $19(35.85 \%)$ \\
$26-35$ years old & $23(44.23 \%)$ & $27(50.94 \%)$ \\
$>=36$ years old & $10(19.23 \%)$ & $7(13.21 \%)$ \\
\hline Monthly income & $1(1.92 \%)$ & $3(5.66 \%)$ \\
$>=€ 1000$ & $32(61.54 \%)$ & $36(67.92 \%)$ \\
$€ 1001-2000$ & $7(13.46 \%)$ & $7(13.21 \%)$ \\
$€ 2001-3000$ & $7(13.46 \%)$ & $5(9.43 \%)$ \\
$€ 3001-4000$ & $5(9.62 \%)$ & $2(3.77 \%)$ \\
$>€ 4000$ & \multicolumn{2}{|l}{} \\
\hline
\end{tabular}

Across both experiments, we manipulated the price of the product with negative sustainability information as a between-subject experiment design. To determine the prices of the twelve grocery products in the online grocery store, we checked the price for each product in the two biggest supermarket chains in the country and assigned the average price of each product to the prices of the products with no information in the online grocery store. Based upon our observation that prices in the supermarkets for sustainable products were on average $20 \%$ more expensive than products with no information, we priced the products with positive sustainability information $20 \%$ above the prices of products with no information. For the pricing of the products with negative sustainability information, half of the participants across both experiments saw the price of the negative information product was $20 \%$ less than the products with no information. In the other half of the participants, the negative information product was priced equal to the product with no information (nontransparent product).

Figure 1 shows a snapshot of the online grocery store as seen by the participants in the first experiment. To avoid a sequential effect, we randomized the sequence in which the twelve grocery products and the three product alternatives were presented to the participants. If the participants closed the web browser and re-entered the online grocery store, they would see 
the same manipulated price as before. The participants in the study were not able to check-out from the store unless they had successfully purchased all twelve products and their purchases did not exceed the amount of money they had in their virtual wallet.

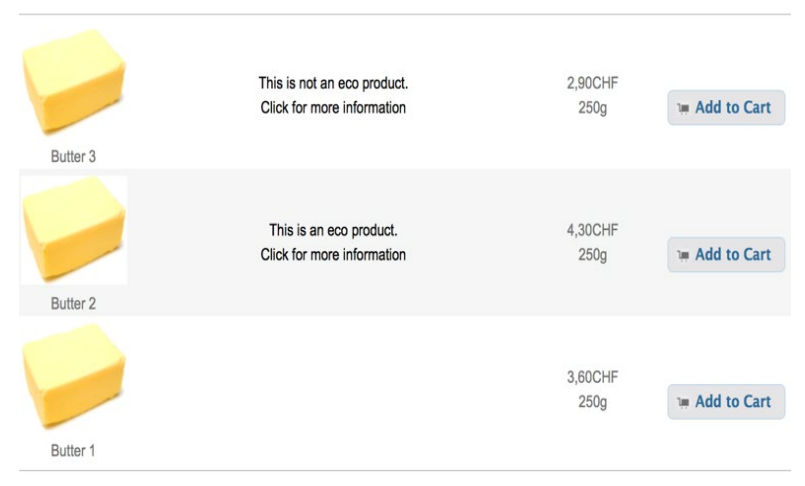

Figure 1. Snapshot of the Generic Information in the Online Grocery Store for the First Experiment

The second experiment presents a series of differences compared to the first experiment: first, the disclosed information contains more specific and elaborate messages. We experimented with both generic (experiment 1) and elaborate (experiment 2) forms of sustainability attribute information disclosure to increase the robustness of our findings, minimize any confounding effects that can be associated with the amount of information that was disclosed, and test $\mathrm{H} 1$ and $\mathrm{H} 2$ respectively. We varied the content of information in experiment 2 according to the 3Ps of environmental sustainability (People, Profit, and Planet), also known as the Triple Bottom Line. Each of the 3Ps reflects social, economic and environmental concerns respectively $[41,42]$. As an example, information relating to the 'People' dimension refer to the use of child labor in the production process, information relating to 'Profit' refer to the adoption of fair working conditions, and finally information relating to 'Planet' refer to the use of agrochemical products in a product's production method.

The sustainability attribute information that is associated with a lower degree of psychological distance refers to the Planet aspect, whereas the sustainability attribute information that is associated with a higher degree of psychological distance refers to the aspects of the People and Profit attribute information. Our logic was that participants are more likely to believe that information around 'Planet' will impact their health and that such information has a higher appeal to individual benefits. Therefore, we associated this type of attribute information with a lower degree of psychological distance. In contrast, information referring to the use of child labor or fair trade working conditions does not impact the quality of consumption directly, but rather relates more to the values of social justice [43], and as a result, we expect these two types of attribute information to be associated with a higher degree of psychological distance, when compared to 'Planet' attribute information.

To confirm this, we conducted a manipulation check with 65 participants with similar demographic characteristics as in our main experiments. To measure the degree of psychological distance among the 3Ps of sustainability, we modified relevant items developed by Spence et al. [44], and created items concerning the geographical, social and temporal distance. We developed one item for each type of psychological distance and maintained consistency across the 3Ps. The items were: "Choosing a product based on the information that is provided to me is likely to: 1) affect the local area that I live in, 2) affect the lives of people who are just like me, 3) affect me in the near future.

Our results (Table 2) confirmed that Planet information has a lower degree of psychological distance compared to People and Profit information, and there is no significant difference between People and Profit information in terms of the perceived psychological distance.

Table 2. Manipulation Check Results for the Second Experiment

\begin{tabular}{|l|c|c|c|c|}
\hline $\begin{array}{c}\text { Attribute } \\
\text { Information }\end{array}$ & $\begin{array}{c}\text { Mean } \\
\text { Diff. }\end{array}$ & $\begin{array}{c}\text { St. } \\
\text { Dev. }\end{array}$ & $t(d f)$ & $p$ \\
\hline Planet vs. People & -0.174 & 0.710 & $-1.980(64)$ & $<0.05$ \\
\hline Planet vs. Profit & -0.205 & 0.661 & $-2.503(64)$ & $<0.05$ \\
\hline Profit vs. People & 0.031 & 0.699 & $0.355(64)$ & $>0.05$ \\
\hline
\end{tabular}

We randomized the allocation of 3Ps messages to the twelve products that the participants had to purchase, i.e., each participant saw four products with similar attribute information around each of the 3Ps (4 products with the same information for Planet, 4 products for Profit, and 4 for People). Hence, while the pricing manipulation was a between-subjects experimental design, the content of the negative information was a within-subjects experimental design. To avoid attribute ordering effects, both the content of the attribute information and the sequence of the grocery products were randomized. Participants were not able to check out unless they had successfully purchased all twelve products and their purchases did not exceed the amount of money they had in their virtual wallet. Figure 2 shows a snapshot of the online store as seen by the participants in this experiment. 


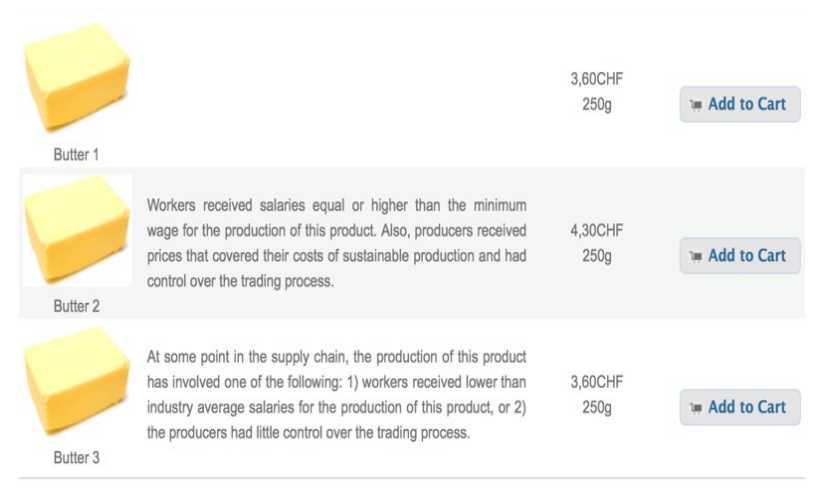

Figure 2. Snapshot of the Detail Information in the Online Grocery Store for the Second Experiment

\section{Results}

Since the dependent variable was the choice among three alternative products, the data was analyzed using generalized structural equation modeling (gsem) - an extension to linear structural equation modeling that allows for multilevel models. To account for the possible choice dependency within the individual participants because of unobserved differences, we nested the gsem function by subject id. We first present the results from the price manipulation across the two experiments. The results regarding the likelihood of choosing a sustainable product over a product with no sustainability attribute information are shown in Table 3 , followed by an overview of the likelihood of choosing a sustainable product over a product with some form of negative attribute information disclosure (Table 4).

Our results reveal that the mere disclosure of sustainability-related information does not appear to influence sustainable product choice (see Table 3). Hence, H1 is supported. Surprisingly, the results show that when the unsustainable product was priced lower than the non-transparent (no information) product, consumers were more likely to opt for the unsustainable product relative to the sustainable product (see Table 4).

The second experiment allows us to test $\mathrm{H} 2$. $\mathrm{H} 2$ is partially supported: the hypothesized relationship holds for the choices between sustainable and non-transparent products when the non-transparent product is priced equally with the unsustainable product (Table 5), but not for the choices between sustainable and unsustainable products (Table 6). In fact, when the unsustainable product is priced lower than the non-transparent product, and the sustainability attribute information is on farmers' economic welfare, consumers tend to prefer the unsustainable product over the sustainable product.
Table 3. Findings from the pricing manipulation, regarding the likelihood of choosing a sustainable product over a product with no attribute information

\begin{tabular}{|l|c|c|}
\hline & \multicolumn{2}{|c|}{$\begin{array}{c}\text { Likelihood of selecting } \\
\text { product with positive } \\
\text { information over product with } \\
\text { no information }\end{array}$} \\
\cline { 2 - 3 } & $\begin{array}{c}\text { Study 1 } \\
\text { (generic info) }\end{array}$ & $\begin{array}{c}\text { Study 2 } \\
\text { (detail info) }\end{array}$ \\
\hline $\begin{array}{l}\text { Control variables } \\
\text { Gender (male (0)) }\end{array}$ & 0.012 & -0.069 \\
Age & -0.023 & 0.155 \\
Income level & 0.163 & 0.100 \\
Main variable & & \\
Price (Product with \\
negative info is priced \\
equal to product with \\
no info (0), product \\
with negative info has \\
the lowest price (1))
\end{tabular}

***: sig. at $\mathrm{p}<0.001, * *$ : sig. at $\mathrm{p}<0.01, *$ : sig. at $\mathrm{p}<0.05$

Table 4. Findings from the pricing manipulation, regarding the likelihood of choosing a sustainable product over an unsustainable product (product with negative attribute information)

\begin{tabular}{|l|c|c|}
\hline \multirow{2}{*}{} & $\begin{array}{c}\text { Likelihood of selecting } \\
\text { product with positive } \\
\text { information over product with } \\
\text { negative information }\end{array}$ \\
\cline { 2 - 3 } & $\begin{array}{c}\text { Study 1 } \\
\text { (generic info) }\end{array}$ & $\begin{array}{c}\text { Study 2 } \\
\text { (detail info) }\end{array}$ \\
\hline $\begin{array}{l}\text { Control variables } \\
\text { Gender (male (0)) }\end{array}$ & 0.760 & 1.285 \\
Age & 0.161 & 0.710 \\
Income level & 0.194 & 0.327 \\
Main variable \\
$\begin{array}{l}\text { Price (Product with } \\
\text { negative info is priced } \\
\text { equal to product with } \\
\text { no info (0), product } \\
\text { with negative info has } \\
\text { the lowest price (1)) }\end{array}$ & $-0.820 *$ & $-2.062 * *$ \\
\hline Log Likelihood & -871.231 & -567.305 \\
\hline ***: sig. at $\mathrm{p}<0.001, * *:$ sig. at $\mathrm{p}<0.01, *$ sig. at $\mathrm{p}<0.05$
\end{tabular}


Table 5. Findings from the combined manipulation, regarding the likelihood of choosing a sustainable product over a product with no attribute information

\begin{tabular}{|c|c|}
\hline & $\begin{array}{c}\text { Study } 2 \\
\text { (detail info) }\end{array}$ \\
\hline \multicolumn{2}{|l|}{ Control variables } \\
\hline Gender (male (0)) & -0.079 \\
\hline Age & 0.150 \\
\hline Income level & 0.102 \\
\hline \multicolumn{2}{|l|}{$\begin{array}{l}\text { Main variables (baseline: product with } \\
\text { negative info is priced equal to product } \\
\text { with no info (price: } 0 \text { ) x economic welfare } \\
\text { message (message: } 0 \text { )) }\end{array}$} \\
\hline $\begin{array}{l}\text { Price: } 0 x \text { social welfare message } \\
\text { (message: } 1 \text { ) }\end{array}$ & 0.631 \\
\hline $\begin{array}{l}\text { Price: } \begin{array}{lll}0 & \mathrm{x} & \text { agrochemical message } \\
\text { (message: } 2 \text { ) }\end{array}\end{array}$ & $1.082 * *$ \\
\hline $\begin{array}{l}\text { Product with negative info has the } \\
\text { lowest price (price: } 1 \text { ) x message: } 0\end{array}$ & $1.079 *$ \\
\hline Price: 1 x message: 1 & -0.761 \\
\hline Price: 1 x message: 2 & $-1.283 * *$ \\
\hline Log Likelihood & -571.277 \\
\hline
\end{tabular}

Table 6. Findings from the combined manipulation, regarding the likelihood of choosing a sustainable product over an unsustainable product (product with negative attribute information)

\begin{tabular}{|c|c|}
\hline & $\begin{array}{c}\text { Study } 2 \\
\text { (detail info) } \\
\end{array}$ \\
\hline Control variables & \\
\hline Gender (male (0)) & 1.319 \\
\hline Age & 0.721 \\
\hline Income level & 0.335 \\
\hline $\begin{array}{l}\text { Main variables (baseline: product with } \\
\text { negative info is priced equal to product } \\
\text { with no info (price: } 0 \text { ) x economic welfare } \\
\text { message (message: } 0 \text { )) }\end{array}$ & \\
\hline $\begin{array}{l}\text { Price: } 0 \quad x \text { social welfare message } \\
\text { (message: } 1 \text { ) }\end{array}$ & 0.809 \\
\hline $\begin{array}{l}\text { Price: } \begin{array}{lll}0 & x & \text { agrochemical message } \\
\text { (message: } 2 \text { ) }\end{array}\end{array}$ & 0.554 \\
\hline $\begin{array}{l}\text { Product with negative info has the } \\
\text { lowest price (price: } 1 \text { ) } \times \text { message: } 0\end{array}$ & $-2.097 * *$ \\
\hline Price: 1 x message: 1 & -0.399 \\
\hline Price: 1 x message: 2 & 0.527 \\
\hline Log Likelihood & -558.948 \\
\hline
\end{tabular}

\section{Discussion}

Our study presents a number of empirical findings and makes several key corresponding contributions. First and foremost, our results show that simply disclosing sustainability attribute information does not necessarily guide consumers towards more sustainable choices. As the sustainability attribute information is associated with higher construal and situated next to another choice parameter that has lower construal, i.e., pricing information, consumers will prioritize the lowconstrual information (price) in making their choice. Indeed, when a product with negative sustainability attribute information had the lowest price, consumers in our study tended to prefer the lower priced nonsustainably product over a more expensive sustainable product.

However, the attributes of the sustainability information make a difference. When a product with negative information was priced equally with a nontransparent product (with no attribute information), and the information was about the use of agrochemical substances, then consumers tended to prefer the sustainable product. The presence (or absence) of agrochemical substances arguably has individual level implications, making the decision as much about the consequences of the environmental practice on the individual as about the consequences of the individual's consumption decision on the environment.

In cases where the sustainability attribute concerned the use of agrochemical substances, we also observed that when an unsustainable product was priced lower than a non-transparent product, consumers tended to prefer the non-transparent product over a more expensive sustainable product. Hence, it seems that consumers make assumptions about the quality of the non-transparent product depending on how it is priced relative to the unsustainable, transparent product.

Another key finding in our analysis is that consumers exhibit variable degrees of sensitivity to the disclosure of sustainability attribute information, depending on the sustainability attributes. Most importantly, we found that the tendency to buy the cheapest, unsustainable product is the strongest when the sustainability attribute is of higher psychological distance to consumers, such as farmers' economic welfare. Consumers seem to generally exhibit a negative sentiment on farmer's economic welfare, or fair-trade, attribute information.

The aforementioned results carry a number of theoretical and empirical implications for the literature on information transparency, the related streams of the literature on online consumer behavior and ethical consumption, as well as the literature on humancomputer interaction. We discuss these in the following sub-sections.

\subsection{Contributions to research}

Our study contributes to the literature on information transparency by examining whether information transparency about products' sustainability attributes foster sustainable consumption choice. We 
adopted a holistic view of transparency and considered the disclosure of both positive and negative facets of attribute information within a choice set.

Drawing our theoretical insights from Construal Level Theory (CLT), we highlight that consumers are not equally sensitive to all types of information: some sustainability attributes appear to be more pertinent and salient than others, especially those appealing to individual benefits (lower psychological distance). Our study therefore indicates that future work on information disclosure should not only focus on the quantity of sustainability information that is being disclosed, but also on the different sustainability attribute information and the implications carried by its disclosure.

The findings of our study further reveal that consumers not only tend to compare the sustainability attribute and pricing information of a certain product, but also draw comparisons among these dimensions between the alternative products. Accordingly, we show that the transparency around negative sustainability attribute information disclosure on the one hand affects the consumers' choice of a product with negative information whereas on the other hand it also influences the choices that consumers make between the other rival products, i.e. products with no information and products with positive information. In the case when the information is pertinent to individual benefits, we observed that this increased transparency influenced consumer behavior in terms of making assumptions and opting for higher quality products.

Our study adds to the literature that examines the influence of retailer-provided sustainability information at the point of purchase. In the context of online purchase and human-computer interaction, future studies can extend our study by adding an online shopping agent to interact with consumers and increase the salience of the sustainability attribute information at the point of purchase. Although we show that some sustainability attributes appear to be less pertinent and salient than others, future studies can investigate whether an online shopping agent can induce transient perceptions of their salience and influence the kind of information consumers use to make purchase decisions.

\subsection{Implications for practice}

The most important implication for practice of our study pertains to the sustainable consumption movement. Our study shows that sustainability attribute information should be framed according to the individual gains that a person will enjoy by consuming a sustainable product, and not as appeals to collective benefits. This finding might also shed light on a recent debate about whether consumers interpret ethical information in a positive or a negative light (cf. [25, 26]). Our study challenges some recent insights from the sustainable consumption industry, namely that individual consumption is primarily driven by product pricing. We argue that the transparency on the product pricing should also be accompanied by an equal amount of transparency on sustainability attribute information in order to reflect true consumer preferences.

Our study also holds a series of implications about how organizations should manage an information transparency strategy. Specifically, we show that the disclosure of some forms of negative sustainability attribute information is not necessarily harmful, provided that it is accompanied by pricing transparency. However, this begs the question of who should be responsible for putting in place such systems for negative attribute information disclosure. While it would seem counterintuitive for firms to self-disclose negative information about their own products, we argue that this should not necessarily be the case, especially in the context of a broader information transparency strategy where firms are not only transparent about their pricing strategies, but also about the different attributes of their product offerings.

However, since most firms do not produce all aspects of their products themselves, the aggregation of the products' sustainability attribute information throughout their supply chains could be costly. For instance, in the context of the food system, the implementation of traceability systems able to trace the location, history, or use of an object [28] can be a viable option for multinational groups with dedicated supply chains, an example of which includes the recent implementation of such a system by Nestlé in order to monitor the animal welfare standards in its supply chain. Unfortunately, the majority of smaller organizations do not have the financial means and the power to implement such initiatives, thus constituting the necessity for high-level coordination, such as some coordination with the governmental stakeholders.

Finally, our study reveals the seemingly lack of trust in fair trade products (i.e., products with economic welfare information). The study of De Pelsmacker, Driesen et al. [45], which examined the behavior of Belgian customers towards fair trade coffee, revealed an attitude-behavior gap with nearly half of the respondents liking the fair-trade coffee but only $10 \%$ of the overall sample willing to pay an extra premium for that. One of the reasons for this might be consumers' concern about whether the fair trade is actually being put into practice. Consumers may only pay a premium price for the fair price products if they are fully assured and confident that they are not just benefiting the company by paying the extra premium for no ascertained benefit to society. 


\subsection{Limitations and suggestions for future research}

Our study does not come short of limitations and possible extensions. To start with, our study was based on an online experiment where we sought to replicate real-life consumer behavior, hence the external validity of our results is threatened to a certain extent. We nevertheless took all possible measures to account for this limitation (e.g. by incentivizing users to take part in the study and by eliminating responses from participants who completed the experiment in a very short amount of time). Moreover, our study is restricted to the context of grocery shopping, therefore the results of our study might not be applicable into other settings; future studies can extend our results into more commoditized product offerings (see [46]). Last, we need to note that the transparent products in our study included either positive or negative attribute information. We need to acknowledge that real life products will tend to encompass both positive and negative information among their attributes. Given that products combining positive and negative attribute information can lead to alternative choice patterns [22], future research can examine the effects of disclosing negative information about some attributes but positive about others across a variety of products in order to enrich our understanding of this burgeoning phenomenon.

\section{Conclusion}

There is a big debate on whether the disclosure of sustainability attribute information can actually influence consumer behavior along the lines of sustainable consumption. Our study sought to examine whether the disclosure of information in an online grocery store can potentially shed light on consumers' sustainable consumption patterns. We tested the effect of sustainability attribute information disclosure on consumer choice in the presence of pricing information. Our study shows that sustainability attribute matters in terms of influencing consumer choice. We are confident that the results of our study will help organizations in managing an information transparency strategy by being less hesitant to disclose information around the sustainability attributes of their products.

\section{References}

[1] E. Geyer-Alléye, and A. Zacarias-Farah, "Towards Sustainable Household Consumption? Trends and Policies in OECD Countries", Organization for Economic Co-operation and Development, 2002.

[2] Elkington, J., "Enter the Triple Bottom Line", in Henriques, A., Richardson, J., (eds.), The Triple Bottom
Line: Does It All Add up? Earthscan, London, 2004, pp. 1-16.

[3] Nielsen, The Sustainability Imperative, 2015, https://www.nielsen.com/wpcontent/uploads/sites/3/2019/04/Global20Sustainability 20Report October202015.pdf [accessed on 22 April 2021].

[4] A.M. Stewart, and J.L. Craig, "Predicting ProEnvironmental Attitudes and Behaviors: A Model and A Test", Journal of Environmental Systems, 28(4), 2000, pp. 293-317.

[5] S.S. Hussain, "Green Consumerism and Ecolabelling: A Strategic Behavioral Model”, Journal of Agricultural Economics, 51, 2000, pp. 77-89.

[6] S. Mueller, L. Lockshin, and J.J. Louviere, "What You See May Not Be What You Get: Asking Consumers What Matters May Not Reflect What They Choose", Marketing Letters, 21(4), 2010, pp. 335-350.

[7] P. Auger, P. Burke, T.M. Devinney, and J.J. Louviere, "What will Consumers Pay for Social Product Features?" Journal of Business Ethics, 42(3), 2003, pp. 281-304.

[8] M. Carrigan, and A. Attalla, "The Myth of the Ethical Consumer - Do Ethics Matter in Purchase Behaviour?" Journal of Consumer Marketing, 18(7), 2001, pp. 560577.

[9] M.G. Luchs, R.W. Naylor, J.R. Irwin, and R. Raghunathan, "The Sustainability Liability: Potential Negative Effects of Ethicality on Product Preference", Journal of Marketing, 74(5), 2010, pp. 18-31.

[10] S. Watts, and G. Wyner, "Designing and Theorizing the Adoption of Mobile Technology-Mediated Ethical Consumption Tools", Information Technology and People, 24(3), 2011, pp. 257-280.

[11] A.M. Degeratu, A. Rangaswamy, and J. Wu, "Consumer Choice Behavior in Online and Traditional Supermarkets: The Effects of Brand Name, Price, and Other Search Attributes", International Journal of Research in Marketing, 17(1), 2000, pp. 55-78.

[12] M.J. Carrington, B.A. Neville, and G.J. Whitwell, "Lost in Translation: Exploring the Ethical Consumer Intention-Behavior Gap", Journal of Business Research, 67(1), 2014, pp. 2759-2767.

[13] J. Hoek, N. Roling, and D. Holdsworth, "Ethical Claims and Labelling: An Analysis of Consumers' Beliefs and Choice Behaviors", Journal of Marketing Management, 29(7-8), 2013, pp. 772-792.

[14] S.M. Broniarczyk, and J.G. Griffin, "Decision Difficulty in the Age of Consumer Empowerment", Journal of Consumer Psychology, 24(4), 2014, pp. 608-625.

[15] Y.K. van Dam, and A.R. Fischer, "Buying Green without Being Seen", Environment and Behavior, 47(3), 2015, pp. 328-356.

[16] Y.K. van Dam, and H.C. van Trijp, "Relevant or Determinant: Importance in Certified Sustainable Food Consumption", Food Quality and Preference, 30(2), 2013, pp. 93-101.

[17] E. Brynjolfsson, "The Contribution of Information Technology to Consumer Welfare", Information Systems Research, 7(3), 1996, pp. 281-300. 
[18] V. Grover, and P. Ramanlal, "Six Myths of Information and Markets: Information Technology Networks, Electronic Commerce, and the Battle for Consumer Surplus", MIS Quarterly, 23(4), 1999, pp. 465-495.

[19] E.K. Clemons, and G.G. Gao, "Consumer Informedness and Diverse Consumer Purchasing Behaviors: Traditional Mass-Market, Trading Down, and Trading Out into the Long Tail", Electronic Commerce Research and Applications, 7(1), 2008, pp. 3-17.

[20] J. Berger, A.T. Sorensen, and S.J. Rasmussen, "Positive Effects of Negative Publicity: When Negative Reviews Increase Sales", Marketing Science, 29(5), 2010, pp. 815-827.

[21] M.D. Angelis, A. Bonezzi, A.M. Peluso, D.D. Rucker, and M. Costabile, "On Braggarts and Gossips: A SelfEnhancement Account of Word-Of-Mouth Generation and Transmission", Journal of Marketing Research, 49(4), 2012, pp. 551-563.

[22] D. Ein-Gar, B. Shiv, and Z.L. Tormala, "When Blemishing Leads to Blossoming: The Positive Effect of Negative Information", Journal of Consumer Research, 38(5), 2012, pp. 846-859.

[23] H. Imkamp, "The Interest of Consumers in Ecological Product Information Is Growing-Evidence from Two German Surveys", Journal of Consumer Policy, 23(2), 2000, pp. 193-202.

[24] L.F. Luna-Reyes, J. Zhang, R. Roy, D.F. Andersen, A. Whitmore, and D.L. Andersen, "Information Strategies to Support Full Information Product Pricing: The Role of Trust", Information Policy, 18(1), 2013, pp. 75-91.

[25] V.S. Folkes, and M.A. Kamins, "Effects of Information about Firms' Ethical and Unethical Actions on Consumers' Attitudes", Journal of Consumer Psychology, 8(3), 1999, pp. 243-259.

[26] K.R. Ehrich, and J.R. Irwin, "Willful Ignorance in the Request for Product Attribute Information", Journal of Marketing Research, 42(3), 2005, pp. 266-277.

[27] Y-N. Cho, and C. Berry, "Understanding the Effects of Retailer- And Manufacturer-Provided Sustainability Labels on Product Evaluations and Purchase-Related Outcomes", Journal of Business Research, 100, 2019, pp. 73-85.

[28] C. Coff, "Ethical Traceability for Improved Transparency in the Food Chain", in Gottwald, F-T., Ingensiep, H.W., Meinhardt, M., (eds.), Food Ethics, Springer-Verlag, New York, 2010, pp. 31-45.

[29] Y. Trope, and N. Liberman, "Construal-Level Theory of Psychological Distance", Psychological Review, 117(2), 2010, pp. 440-463.

[30] Y. Bar-Anan, N. Liberman, and Y. Trope, "The Association between Psychological Distance and Construal Level: Evidence from an Implicit Association Test”, Journal of Experimental Psychology, 135(4), 2006, pp. 609-622.

[31] U. Khan, M. Zhu, and A. Kalra, "When Trade-Offs Matter: The Effect of Choice Construal on Context Effects", Journal of Marketing Research, 48(1), 2011, pp. 62-71.
[32] N. Liberman, and Y. Trope, "The Role of Feasibility and Desirability Considerations in Near and Distant Future Decisions: A Test of Temporal Construal Theory", Journal of Personality and Social Psychology, 75(1), 1998, pp. 5-18.

[33] T.H. Freling, L.H. Vincent, and D.H. Henard, "When not to Accentuate the Positive: Re-Examining Valence Effects in Attribute Framing", Organizational Behavior and Human Decision Processes, 124(2), 2014, pp. 95109.

[34] R.M. Dawes, and D.M. Messick, "Social Dilemmas", International Journal of Psychology, 35, 2000, pp. 111116.

[35] M.O. Wood, T.J. Noseworthy, and S.R. Colwell, "If You Can't See the Forest for the Trees, You Might Just Cut down the Forest: The Perils of Forced Choice on "Seemingly" Unethical Decision-Making", Journal of Business Ethics, 118(3), 2013, pp. 515-527.

[36] N. Granados, A. Gupta, and R.J. Kauffman, "Research Commentary-Information Transparency in Business-toConsumer Markets: Concepts, Framework, and Research Agenda", Information Systems Research, 21(2), 2010, pp. 207-226.

[37] H.C. Lucas, R. Agarwal, E.K. Clemons, O.A. El Sawy, and B. Weber, "Impactful Research on Transformational Information Technology: An Opportunity to Inform New Audiences", MIS Quarterly, 37(2), 2013, pp. 371382.

[38] O. Mintz, I.S. Currim, and I. Jeliazkov, "Information Processing Pattern and Propensity to Buy: An Investigation of Online Point-Of-Purchase Behavior", Marketing Science, 32(5), 2013, pp. 716-732.

[39] Louviere, J. J., Hensher, D. A., and Swait, J. D, Stated Choice Methods: Analysis and Applications, Cambridge University Press, UK, 2000.

[40] D. McFadden, "The Choice Theory Approach to Market Research", Marketing Science, 5(4), 1986, pp. 275-297.

[41] V. Dao, I. Langella, and J. Carbo, "From Green to Sustainability: Information Technology and an Integrated Sustainability Framework", Journal of Strategic Information Systems, 20(1), 2011, pp. 63-79.

[42] N.P. Melville, "Information Systems Innovation for Environmental Sustainability”, MIS Quarterly, 34(1), 2010, pp. 1-21.

[43] S. Hartlieb, and B. Jones, "Humanising Business through Ethical Labelling: Progress and Paradoxes in the UK", Journal of Business Ethics, 88(3), 2009, pp. 583-600.

[44] A. Spence, W. Poortinga, and N. Pidgeon, "The Psychological Distance of Climate Change", Risk analysis, 32(6), 2012, pp. 957-972.

[45] P. De Pelsmacker, L. Driesen, and G. Rayp, "Do Consumers Care about Ethics? Willingness to Pay for Fair-Trade Coffee“, Journal of Consumer Affairs, 39(2), 2005, pp. 363-385.

[46] T. Li, R.J. Kauffman, E. van Heck, P. Vervest, and B.G. Dellaert, "Consumer Informedness and Firm Information Strategy", Information Systems Research, 25(2), 2014, pp. 345-363. 